ENSAIO

Recebido em: $17 / 05 / 2017$

Aceito em: 04/12/2017

\title{
Documento e institucionalidades: dimensões epistemológica e política
}

\author{
Document and institutionalities: epistemological and political dimensions
}

Rodrigo RABELLO (rdgrabello@gmail.com)*

* Professor da Faculdade de Ciência da Informação - UnB.

Resumo: Problematiza o conceito documento em disciplinas que privilegiam a ênfase nas características de fisicalidade do suporte para alguma finalidade prática. Argumenta a necessidade de complementaridade a tais construtos no sentido de buscar caminhos de compreensão do fenômeno holisticamente, lançando as seguintes hipóteses: a) a materialidade do documento é ulterior à fisicalidade do suporte; b) o documento se constitui como um produto de práticas sociais, envolvido por diferentes institucionalidades. A reflexão sobre a relação simbiótica entre materialidade do documento e práticas sociais e institucionalidades é precedida do questionamento da epistemologia como espaço meta-discursivo, encontrando no componente político uma alternativa complementar e estratégica. Busca compreender o documento como objeto com valor social (fonte de informação ou evidência), tendo em vista, dentre outros aspectos, a autoridade do sujeito que valida o objeto nalgum contexto institucional. Objetiva, ainda, demonstrar que a materialidade do documento tem sua identidade determinada por sua função documental e por práticas sociais que lhe conferem valor político. Para tanto, encontra subsídio em aspectos abordados nas obras de Michel Foucault e de Maria Nélida Gonzáles de Gómez, considerando variáveis presentes desde a concepção de valores documentais até a validação da informação para a transformação do objeto em documento. Consideram, nessa direção, regimes, ações e práticas informacionais, num espaço interpretativo direcionado à tentativa de compreensão de empreendimentos epistemológicos e políticos de algum modo tocados, institucionalmente, pela relação saber-poder.

Palavras-chave: Documento. Institucionalidade. Relação saber-poder. Epistemologia. Política.

Abstract: This paper problematizes the concept 'document' in disciplines prioritizing the emphasis on the characteristics of physicality of the support for a practical objective. It points the need to complement such constructs meaning to seek ways of comprehending the phenomenon holistically, casting the following hypotheses: a) the materiality of the document is ulterior to the physicality of the support; b) the document is constituted as a product of social practices, surrounded by different institutionalities. The reflection on the symbiotic relation among the materiality of the document, social practices, and institutionalities is preceded by the questioning of the epistemology as a metadiscursive space, finding in the political component a complementing strategic alternative. It seeks to comprehend the document as an object with social value (source of information or evidence), considering, among other aspects, the authority of the subject who validates the object in an institutional context. It aims also to demonstrate that the materiality of the document has its identity determined by its documental function and by social practices conferring political value to it. Hence, it finds subsidy in aspects approached in the works by Michel Foucault and Maria Nélida Gonzáles de Gómez, considering variables found ranging from the conception of documental values to the validation of information transforming the object in a document. They consider, thus, informational practices, actions, and regimes, in an interpretative space aiming to attempt to comprehend political and epistemological undertakings somehow regarded, institutionally, by the power-knowledge relation.

Keywords: Document; Institutionality; Power-Knowledge Relation; Epistemology; Politics.

v. 23, n. $51,2018$. p. $138-156$

ISSN 1518-2924
Esta obra está licenciada sob uma Licença Creative Commons 


\section{INTRODUÇÃo}

Campos do saber que têm o documento como objeto de estudo - para citar alguns: história, diplomática, arquivologia, biblioteconomia, documentação, ciência da informação - tendem, segundo epistemologias particulares, a interpretá-lo como suporte que contém informação registrada, suporte que evidencia fatos, fonte para a representação da realidade, fonte para a elaboração de metainformação ou produtos documentais com a finalidade de organização, recuperação e uso de conteúdos em sistemas de informação, dentre outros entendimentos. Tais enunciados trazem pistas sobre a constituição do documento e tendem a focar características da fisicalidade do suporte para alguma finalidade prática.

Existem, por sua vez, ao menos outros dois enunciados que auxiliam a compreender o documento holisticamente e que merecem ser investigados: a) a materialidade do documento é ulterior à fisicalidade do suporte; b) o documento se constitui como um produto de práticas sociais, envolvido por diferentes institucionalidades. Tais enunciados têm como mérito o fato de que o primeiro traz nas palavras materialidade e documento valores em correspondência às expressões nucleares do segundo enunciado, práticas sociais e institucionalidades.

A materialidade do documento em sinergia às interpretações das práticas sociais e das institucionalidades revela não apenas a necessidade de epistemologias alternativas com interesse em pesquisa fundamental ou básica, mas, até mesmo, a possibilidade de questionamento da epistemologia como espaço metadiscursivo ou lugar de interpretação pública dos campos do saber, encontrando no componente político uma alternativa complementar e estratégica.

0 componente político será abordado complementarmente à dimensão epistemológica em algo que pode ser pensado como uma "dupla hermenêutica" (GONZÁLEZ de GÓMEZ, 1999/2000) para o estudo das institucionalidades constituídas e constituintes de valores do documento no sentido de operacionalizar modos de validação da informação. Em particular, são de interesse os valores expressos em práticas sociais respaldadas por saberes institucionais que legitimam discursos (RABELLO; RODRIGUES, 2014; 2016) num processo de validação dos objetos para a sua transformação em documento, também expresso, em sua politicidade, na condição de monumento (FOUCAULT, 2005; LE GOFF, 1994).

Busca, com essa trajetória, subsídios para compreender o documento como objeto com valor informativo (HJORLAND, 2000) à luz da sua potencialidade de fonte de informação ou evidência (BUCKLAND, 1991), cuja autoridade de validação do sujeito ao objeto em algum contexto institucional é, de modo ideal, reconhecida por outrem, permitindo a atribuição de sentidos diversos, dentre os quais o de valor probatório no âmbito acadêmico-disciplinar.

Depreende, ainda, que a materialidade do documento transcende a fisicalidade do objeto, haja vista se apresentar como uma expressão material dos enunciados que circulam socialmente e provocam práticas sociais e em contextos institucionais (FROHMANN, 2008). Nesse sentido, o documento tem sua identidade determinada, em parte, por sua função documental. Com efeito, o documento, como o produto de práticas sociais, encontra, nalguma medida, peso político.

A emergência do olhar holístico sobre o documento como um fenômeno social encontra subsídio em aspectos abordados nas obras de Michel Foucault e de Maria Nélida Gonzáles de Gómez, onde se identificam variáveis a serem consideradas desde a concepção de valores documentais até a validação da informação para a transformação do objeto em documento. Consideram-se, nessa direção, regimes, ações e práticas informacionais, num espaço interpretativo direcionado à tentativa de compreensão de 
empreendimentos epistemológicos e políticos de algum modo tocados, institucionalmente, pela relação saber-poder.

A linha argumentativa que se segue está estruturada em três seções centrais. A primeira delas aborda a "dupla hermenêutica" como caminho promissor de investigação do documento para, na seção seguinte, identificar "alcances da materialidade" do documento, algo complementarmente explorado na seção que antecede as considerações finais em termos de "institucionalidades".

\section{DOCUMENTO E “DUPLA HERMENÊUTICA"}

0 documento pode ser apreciado tendo em vista, dentre outros aspectos, o "aprisionamento" da palavra ou do registro num objeto, considerando, além do suporte, a forma documental, ou a partir da crença na possibilidade de se "representar" inequivocamente a realidade social, tendo o documento como fonte, ou, ainda, da possibilidade de se reconhecer a monumentalidade do documento quando este serve de recurso para a "legitimação de discursos". Tais valores são importantes para a reflexão sobre o lugar de observação ou o empenho teleológico do observador que busca compreender o documento como fenômeno social (RABELLO; RODRIGUES, 2014).

Assim, o documento, como produto e/ou fonte de representação, tem relevância epistemológica, como construto, para diferentes disciplinas acadêmicas. Nesse caso, a epistemologia se apresenta como campo de interpretação, de atualização e de revisão, ou seja, como espaço meta-explicativo sobre a ciência e seus objetos. Isso tem resultado, com efeito, no questionamento do lugar que define o que é ciência e o que é científico a partir do primado da positividade de saberes sobre a natureza ou sobre os critérios metódicos de representação do real.

González de Gómez (2000), no entanto, apresenta uma crise da epistemologia, sobretudo a partir das contribuições de Ludwig Joseph Johann Wittgenstein. Nessa direção, a autora aborda o desafio da epistemologia, tomando como exemplo o conceito informação, também recepcionado como objeto da ciência da informação. A informação, nesse contexto, se constituiria com um caráter estratificado e transversal, em relações inter/transdisciplinares, com positivação conceitual dificultada haja vista seu estado de "indecibilidade estrutural" e sua configuração em diferentes "modelos sociotécnicos". Esse percurso é relevante haja vista que ao conceito informação, dentre outros aspectos, é atribuída posição nuclear para a constituição do documento.

As ciências modernas, sobretudo as humanas e sociais, têm enfrentado uma crise metadiscursiva, algo que tem sido objeto de interesse da epistemologia. Não obstante, a própria epistemologia também se apresenta como espaço metadiscursivo em crise, tendo em vista a atual dificuldade de interpretação da noção de "cientificidade" a partir dos desafios colocados, por exemplo, no plano da linguagem, expresso na "virada linguística", que tem o filósofo Wittgenstein como um de seus principais expoentes.

No ocidente, a ciência se apresentou como a "voz" oficial da apreensão e da explicação (preferencial e imperativa) do "mundo real". Além disso, em diversificadas arenas metadiscursivas ocorreram disputas pela definição da própria cientificidade e foi a "[...] epistemologia que durante muito tempo reclamou para si o direito e a competência de dizer da ciência um algo a mais que ela não disse e nem compreende acerca dela mesma." (GONZÁLEZ de GÓMEZ, 2000, p. 2). A partir dessa complexa função, a epistemologia enfrentou uma dupla tarefa: a) estabelecer o que é ciência (o todo); e b) buscar uma hierarquia e uma classificação (estudo das partes mediante uma 
valorização referencial e analítica) para a composição das disciplinas que formarão aquele todo.

Seguindo esse raciocínio, o controle metodológico possibilitaria a comensurabilidade de conceitos e teorias, sustentando-se, por fim, numa formalização lógica da linguagem para sua utilização no processo argumentativo. Entretanto, o conceito de paradigma científico de Thomas Kuhn, na consideração da universalidade da linguagem, demonstra a fragilidade desse controle à luz dos pressupostos trazidos por Wittgenstein. Tal fragilidade tem por fundamento a impossibilidade de existência de uma linguagem universal, capaz de sintetizar as demais. Desse modo, a epistemologia perderia a sua autoridade, pois nenhum saber, a partir da perspectiva de Wittgenstein, teria autoridade para legitimar outro como científico e objetivo, perdendo o privilégio exclusivo de ser o "saber julgador" ao se situar como o lugar de uma "interpretação pública".

Para além das iniciativas normativas, as tomadas de decisões relativas à política científica e a conformação epistemológica passaram, à luz da instabilidade exposta por González de Gómez (2000), a ser justificadas posteriormente. Numa palavra, o distanciamento da noção de formalidade científica - centrada na noção de linguagem objetiva, universal e comensurável - prescinde de tornar opaco algo que a epistemologia ainda contribui para a concepção de ciência: a propriedade de a ciência estar em contínuo processo de construção, mediante o constante exercício de "por à prova" teorias e métodos válidos, algo que a diferencia do caráter dogmático, por exemplo, mítico-religioso.

A complexidade que envolve o lugar de intepretação da epistemologia pode ser analisada, portanto, numa dimensão metodológica, em cujos diversos nexos advêm do reconhecimento de premissas "poliepistemológicas" (GONZÁLEZ de GÓMEZ, 1999/2000), abarcando, além da política e do conhecimento técnico e científico, outros horizontes, como as dimensões econômica e ética (GONZÁLEZ de GÓMEZ, 2015), num ambiente teórico e metodológico propício para o denominado discurso "pósepistemológico" (GONZÁLEZ de GÓMEZ, 2016).

Ao tematizar as premissas "poliepistemológicas", a autora problematiza, no âmbito metodológico, a ideia de existência de um único programa de investigação para a ciência da informação, questionando, para a disciplina, algo com um único núcleo ou objeto de estudo - como é o caso da informação - ao destacar a influência e/ou a consequência da escolha heurística para a intervenção no campo à luz da "dupla hermenêutica", de cunho "epistemológico" e "político" (GONZÁLEZ de GÓMEZ, 1999/2000).

A "dupla hermenêutica" pode contribuir para o estudo do documento ao permitir a investigação das institucionalidades daqueles que o validam e das instituições que assim o recepcionam, como os arquivos, as bibliotecas, os laboratórios, os museus, os cartórios, dentre outras. Nesse contexto, a linguagem tem papel relevante empregada segundo forças sociais que delineiam a construção da memória coletiva e que instrumentalizam a escrita da história (SCHWARTZ; COOK, 2004) e outros modos de representação da realidade.

Os campos científicos encontram nas fontes documentais validadas (identificação de objetos, análise, avaliação, certificação e julgamento) e, por conseguinte, selecionadas por seus saberes metódicos e técnicos, valor em algo com sentido - informação - e que evidencia algum fenômeno que possa ser traduzido em termos probatórios no âmbito acadêmico-disciplinar. Isso porque o conhecimento científico busca classificar e representar os fenômenos naturais ou sociais por intermédio de procedimentos metódicos, levando à noção de positividade do 
conhecimento, cuja referência remonta os empreendimentos do início da ciência moderna.

Nessa direção, faz-se oportuno ressaltar que nos setecentos houve o surgimento de uma acepção científica taxonômica desenvolvida no bojo dos empreendimentos da história natural, caracterizando-se como um "[...] espaço aberto na representação por uma análise que se antecipa à possibilidade de nomear." (FOUCAULT, 1999, p. 178). Essa historiografia iniciou um novo modo de intervenção, mediante o estudo dos seres vivos. Trouxe um ordenamento e um olhar acurado sobre as coisas, que passaram a ser classificadas e transcritas sob o imperativo da fidedignidade e da neutralidade das ações. "E é nesse tempo classificado, nesse devir quadriculado e especializado que os historiadores do século XIX se empenharão em escrever uma história enfim 'verdadeira'." (FOUCAULT, 1999, p. 180-181).

A partir desse raciocínio, posteriormente reiterado por Souza e Murguia (2012), a classificação apresenta uma forma de ordenamento cuja disposição relacional permite que os objetos possam adquirir vínculos significativos entre si, sejam vínculos entre objetos naturais ou artificiais (MURGUIA, 2010, p. 133). Há, nesse contexto, o pressuposto de que alguém com autoridade detém o poder de dizer que algo pode ou não ser fonte para a representação da realidade. Criam-se práticas mediante as quais os discursos são legitimados. 0 documento serve de prova, mas não deixa de ser um valor, uma escolha ou - para usar uma expressão empregada por Foucault (2005) e reiterada e aprofundada por Le Goff (1994) - um monumento.

0 documento-monumento sintetiza e provoca a reflexão sobre as institucionalidades envolvidas na transformação do objeto em algo com valor social, não apenas em algo com valor acadêmico-disciplinar, mas também político. As fases da arqueologia e da genealogia, que compõem parte significativa da obra de Michel Foucault, podem ser profícuas para a realização de pesquisas que consideram a simultaneidade de interesses epistemológicos e políticos tocantes à busca do entendimento dessas diferentes institucionalidades.

Ambas as fases são complementares, de modo que “[...] Não há pré e pósarqueologia ou genealogia em Foucault. Contudo, o peso e a concepção destas abordagens mudaram no decorrer do seu trabalho." (DREYFUS; RABINOW, 1995, p. 116, grifos dos autores). Portanto, a arqueologia apresenta aparentemente força epistemológica e a genealogia força política. Há de se ponderar que, nesta última fase, o sentido hermenêutico fora em grande medida questionado em meio à pluralidade de possíveis interpretações.

A arqueologia tem como objeto teórico as práticas discursivas ou o discursoobjeto (compreendido com um conjunto de enunciados de um mesmo sistema de formação), com vistas a descrever por que os discursos, num dado momento, são orientados estrategicamente por determinados formalismos. A descrição acolhe e faz funcionar ou excluir, esquecer ou desconhecer a estrutura formal do discurso conjunturalmente conformada (DREYFUS; RABINOW, 1995).

A genealogia se caracteriza pela priorização da prática ante a teoria (arqueologia). Nesse contexto, o sujeito investigador não se constitui como o expectador desligado dos monumentos discursivos mudos, à medida que passa a "[...] diagnosticar $\mathrm{e}$ compreender o significado das práticas sociais a partir do seu próprio interior." (DREYFUS; RABINOW, 1995, p. 115), assim como diagnosticar o "biopoder", entendido como o conjunto de práticas históricas que produz os objetos humanos sistematizados pelo estruturalismo e os sujeitos humanos explicados pela hermenêutica.

A relação saber-poder é um construto aprofundado nas formulações genealógicas abordadas, dentre outras ocasiões, quando Foucault iniciou a depreender, 
primeiro, sobre as relações entre saber biológico e o poder moderno e, segundo, acerca das ciências humanas e sociais, quando "[...] a genealogia pode perguntar sobre o papel histórico e político desempenhado por estas ciências." (DREYFUS; RABINOW, 1995, p.130-131) e acerca da formação de tecnologias disciplinares do corpo.

Nessa perspectiva, o corpo passa a ser analisado como suporte onde as relações de poder operam, seja o corpo produtivo e/ou submisso. O corpo é formado e construído por regimes, "[...] ele é destroçado por ritmos de trabalho, repouso e festa; ele é intoxicado por venenos [...]" (FOUCAULT, 2002, p. 27); há alguma tecnologia política e mecanismos que se inter-relacionam com o Estado e com instituições particulares, num fenômeno denominado de microfísica do poder. 0 documentodocumento não seria uma expressão de tal microfísica?

A "dupla hermenêutica" assume, nesse horizonte interpretativo, o relevante desafio de compreender a "legitimação de discursos", constituído e constituinte dos valores produzidos por diferentes epistemes e institucionalidades e pela relação saberpoder, sintetizada, nalguma medida, no binômio documento-monumento. Tal fenômeno permite compreender as eletividades, mediadas pela linguagem, circunscritas institucionalmente e expressas em termos de materialidade do documento e de práticas sociais mediante as quais os discursos são legitimados.

\section{ALCANCES DA MATERIALIDADE}

A perspectiva da "legitimação de discursos" realoca ou descentraliza, sem prescindir de negar, o entendimento de documento focado na fisicalidade do suporte (matéria + forma + conteúdo temático/descritivo), isto é, como "coisa" ou suporte que contém evidência/registro (BUCKLAND, 1991) com abrangência à possiblidade de representação e produção de índices (BRIET, 1951) no bojo do estrato "informacional ou semântico" (GONZÁLEZ de GÓMEZ, 1999) para fins de organização, recuperação e uso (MEYRIAT, 1981) em instituições informativas e documentais ou de memória (HJORLAND, 2000).

Essa fisicalidade, quando não concebida em possíveis inter-relações - ou seja, desconsiderando outros estratos de informação e forças que governam infraestruturas e redes - tende a não contemplar outros alcances da materialidade do documento. 0 estudo do documento no contexto institucional passa pelo interesse de objetos potencialmente informativos e, por vezes, as "[...] naturezas intrínsecas desses objetos são relativamente irrelevantes." (HJORLAND, 2000, p. 39). 0 estudo de tal potencialidade informativa aponta para a difícil tarefa relacionada à circunstancialidade e à situacionalidade da informação, seja como evidência ou representação de eventos (espontâneos ou recriados) ou naquilo que pode, segundo " $n$ " variáveis, ser definido com pertinente e significante (BUCKLAND, 1991).

A concepção holística da materialidade do documento - pressuposta nas variáveis presentes na transformação do objeto em algo com valor social e institucional - pode se beneficiar de possíveis interpretações que congregam perspectivas políticas e epistemológicas, considerando ao menos 11 (onze) caminhos que podem se intercruzar, a saber: a) institucionalidade, b) cultura material, c) regimes de informação, d) ações de informação, e) práticas informacionais, f) validação da informação, g) estudo da forma documental, h) historiografia, i) burocracia, j) materialidade da informação, k) desenvolvimento de coleções, l) organização do conhecimento. Cada um desses caminhos será abordado brevemente a seguir, numa espécie de "glossário".

A institucionalidade depreende da situação ou do espaço formal (ou menos formal) onde ocorre a objetivação de atributos ou valores aos objetos por aqueles que 
os produzem, em termos, por exemplo, de autoridade epistêmica (GONZÁLEZ de GÓMEZ, 2007), os coletam, os organizam e os armazenam - ações incidentes a algo, a algum objeto que pode ser traduzido na noção de patrimônio (GRIGOLETO; MURGUIA, 2013) - ou os utilizam, tendo em vista o reconhecimento de alguma autoridade e/ou relevância da informação que possa ser útil e culminar na sua apropriação para a produção de conhecimento. Nesse contexto, o documento pode apresentar funções as mais diversas - fonte de ensino/instrução para a transmissão e obtenção de conhecimento, para a memória social ou coletiva, para a prova, dentre outras - próprias a sua criação ou atribuídas posteriormente ao objeto.

A cultura material antecede, acompanha ou auxilia a explicar fenômenos da institucionalidade dos objetos, à medida que remete aos testemunhos da presença e da intervenção do homem no meio ambiente e nos objetos ali presentes, em dessemelhantes contextos socioculturais. Quando tomada como objeto de estudo no âmbito científico, no século XIX os estudos sociológicos de Émile Durkheim contribuíram ao se voltarem a mecanismos gerais do funcionamento das coletividades humanas; estudos arqueológicos marcaram uma mudança paradigmática quando deixaram de considerar artefatos da pré-história, ossadas e utensílios (BUCAILLE; PESEZ, 1989); estudos historiográficos, sobretudo após as contribuições dos Annales, têm ocupado o lugar dos arqueólogos ao estudar os fenômenos pós-invenção da imprensa (BURKE, 1992). A dimensão política, econômica e ética dos objetos e artefatos - quando concebidos como documento-monumento (LE GOFF, 1994) e/ou como mercadoria (APADDURAI, 1991) - pode ser apreciada em termos de regimes de informação.

Os regimes de informação, em expressão de inspiração foucaultiana empregada por Frohmann (1995), podem ser compreendidos, numa concepção particular de González de Gómez (2003), como o modo de formação social dominante que define a maneira de produção da informação em vigor em determinado lugar, tempo e conjuntura. Inscrevem-se em possibilidades culturais e condicionados a relações de poder. Delineiam ou influenciam a ação dos sujeitos, das organizações, das regras e das autoridades. Orientam ou direcionam a escolha dos meios e dos recursos informacionais preferenciais, bem como os critérios de padronização da informação referencial ou de excelência. Padronizam as maneiras de organização, interação e distribuição da informação, constituindo redes, formais e informais, relativamente estáveis, operacionalizadas mediante ações de informação.

As ações de informação, em construto respaldado em parte pela teoria da ação social de Max Weber e na teoria da ação comunicativa de Jürgen Habermas, correspondem a uma perspectiva situacional que não privilegia o cognitivismo embora, em estudo original de Wersig e Windel (1985), essa perspectiva tenha sido uma clara influência - a partir de abordagens individual e coletiva. Tais ações derivam de variáveis de ordem política e ética presentes em estratos diversificados (GONZÁLEZ DE GÓMEZ, 1999): "informacional ou semântico" (pragmático), "dispositivos de informação" (tecnológico) e "metainformacional ou infraestrutural" (regulatório), formando zonas de interseção tecnológicas de transmissão cultural (narrações), integração social (configuração de coletivos; acordos e solidariedade) e de socialização (identificações) (GONZÁLEZ DE GÓMEZ, 2012).

Esses estratos podem ser pensados, em sua particularidade, em termos de práticas informacionais e correspondem a modos de operação nos regimes de informação por meio dos quais as ações, em analogia à premissa informacional apresentada por González de Gómez (1999), podem também desvelar qual é o caso em que o objeto, valorado como documento, será o caso. Nas palavras de González de Gómez 
(1999/2000, p. 337), pode-se dizer que “[...] uma ação de informação antecipa e condiciona a concepção ou aceitação de algo como informação - tal como a ação de documentar antecipa e condiciona o que será produzido e reconhecido como documento."

As práticas informacionais podem anteceder o uso da informação (SAVOLAINEN, 2007). Elas podem ser concebidas como a extensão ou especificação das ações de informação, ou seja, quando estas são pensadas em contextos cotidianos, profissionais e/ou epistêmicos. Por exemplo: o estrato "informacional ou semântico" corresponde, dentre outras práticas, ao âmbito do tratamento da informação em instituições específicas (indexação em biblioteca, classificação em arquivo, representação descritiva em museu etc.); o estrato dos "dispositivos de informação" corresponde, dentre outras práticas, à criação de instrumentos particulares, às tecnologias diversas, às linguagens documentais (sistemas de classificação, tesauros, ontologias etc.); o estrato "metainformacional ou infraestrutural" corresponde às políticas de informação diversas e/ou amplas, como àquelas que se situam no bojo de políticas em ciência e tecnologia, direcionadas, por exemplo, às práticas relacionadas ao acesso aberto, à ciência aberta, em contextos institucionais particulares, somando-se a outras políticas específicas, como as de desenvolvimento de coleções, de organização, de disseminação da informação, dentre outras.

A validação da informação, pressuposta em tais práticas, incide, nalguma medida, na criação ou apropriação de valores para a transformação do objeto em documento. 0 processo validação pode ser pensado, dentre outros aspectos, em termos de relevância na recuperação da informação (SARACEVIC, 2009) e de elementos intrínsecos que conferem credibilidade aos objetos, ou em termos da ação dos sujeitos gnosiológicos em sua autoridade cognitiva que permite compreender os produtos ou indícios de autoria (RIEH; BELKIN, 1998; RIEH, 2002; RIEH; DANIELSON, 2007), ou no bojo das autoridades epistêmicas distribuídas em rede, segundo formas epistêmicas e sociais heterogêneas, envolvendo atores em campos científicos, econômicos e sociais (GONZÁLEZ DE GÓMEZ, 2007).

Tal dimensão pode se beneficiar de estudos dos documentos em perspectivas que consideram não apenas os conteúdos objetivados ou a dimensão física do objeto, mas também a forma documental e os valores de monumentalidade, onde incide, com certa evidência, a relação saber-poder. Com efeito, o documento-monumento pode exteriorizar, quando questionado com ferramentas teóricas e metodológicas, as ações e práticas informacionais circunscritas em regimes de informação particulares, que se constituem como regimes de poder e de verdade.

0 estudo da forma documental, no âmbito da diplomática, pode ser considerado um dos primeiros saberes sistematizados para uma espécie de "validação da informação" com o objetivo de investigar o modo "estilizado" do documento segundo o qual o teor documental ou conteúdo se apresentam para a resolução de um determinado problema administrativo, jurídico ou histórico. A forma documental ambiciona abranger a constituição do documento, contemplando a relação do teor documental com a matéria (NÚÑEZ CONTRERAS, 1981) e em termos de elementos internos e externos em conteúdos autênticos provenientes de uma determinada origem (DURANTI, 1995). A autenticidade iniciou a ser investigada por intermédio da "arte" da crítica documental sistematizada por Jean Mabillon, na obra De re diplomática libri six, de 1681, e aprofundada posteriormente por autores como René Tassin, Charles Toustain, Theodor von Sickel, Julius Ficker, dentre outros (TOGNOLI, 2013).

A partir da então denominada autenticidade diplomática, o documento pode ser analisado considerando a evidência obtida no próprio documento (interesse da 
diplomática) ou daquela obtida na relação entre conjuntos de documentos. Ambas as perspectivas podem ser de interesse para o campo historiográfico. Apenas no último caso - documento em conjunto/relação - se constitui o interesse da arquivologia ou da diplomática contemporânea para a análise instrumental da autenticidade dos documentos com vistas à organização e à representação da informação para fins de recuperação, acesso e uso. 0 documento produzido ou armazenado no âmbito institucional e a possibilidade de análise científica de sua autenticidade passaram a representar um valor para a extração da verdade a partir da palavra ou do registro "aprisionado", sobretudo para os empreendimentos historiográficos quando buscaram elevar a história ao status de ciência (RABELLO; RODRIGUES, 2014).

Os movimentos historiográficos dos séculos XIX e XX instrumentalizaram a "extração" de conteúdos dos documentos em ao menos duas perspectivas distintas. A dimensão positivista parte da crença de que a positividade obtida com a aplicação do método científico, dentre eles, o diplomático (BLOCH, 1997), permite encontrar a essência da verdade no documento a partir da sua autenticidade para a representação inequívoca da realidade. Para outra dimensão, defendida pelos teóricos dos Annales, dentre os quais os pioneiros Marc Bloch e Lucien Febvre, o investigador pode se aproximar do real a partir da interpretação dos objetos por intermédio de alguma institucionalidade ou de algum conhecimento metódico mediante o qual busca interpretar o que, quando, em que lugar e como o objeto deve ser considerado documento (BURKE, 1992; RICOEUR, 2007; GINZBURG, 2011).

Para além de servir de fonte para a historiografia positivista do século XIX, a autenticidade do documento passou a auxiliar e a convergir com o interesse de controle documental no contexto da burocracia moderna, ao se considerar a forma dos documentos administrativos e jurídicos arquivados nas esferas pública e privada. Sobretudo a arquivologia se ocupou dessa função.

A burocracia representa o domínio racional legal, isto é, constitui o meio pelo qual o Estado moderno age, guardadas as exceções, mediante a lei. É, portanto, a expressão racional desse Estado. Com a burocracia, o Estado gere o poder (MALISKA, 2006). O coletivismo constitutivo da burocracia tem em conta uma relação entre o Estado (todo universal) e a parte (indivíduo). Nesses termos, a burocracia pode ser definida como "[...] sistema de condutas significativas e não só um sistema de organização formal." (TRAGTENBERG, 1985, p.187-188).

Como expressão simbólica de poder do Estado (BOURDIEU, 1996), a racionalidade burocrática na administração moderna encontra, num de seus princípios, “[...] documentos escritos ('os arquivos'), preservados em sua forma original ou em esboço." (WEBER, 2002, p. 230). 0 arquivo, como um tipo ideal para o estabelecimento de uma "rigorosa organização burocrática", constitui-se como algo essencial, pois o seu conhecimento se insere como virtude para eficiência da administração (WEBER, 2002), algo que, naturalmente, desperta o interesse da arquivologia (FONSECA, 2005) como um saber interessado nas técnicas e métodos operacionalizados na organização burocrática onde a informação também se materializa.

A materialidade da informação pode ser pensada, segundo Bernd Frohmann, a partir de uma leitura da arqueologia foucaultiana que o leva a considerar o documento como uma expressão material que permite a correspondência entre informação e seu caráter social e público, em diferentes campos e práticas. Os estudos dos efeitos da materialidade da informação na coletividade, com base na materialidade dos enunciados, traz um contraponto às análises "mentalistas", que operam apenas no plano individual. 
Tal materialidade "[...] não consiste simplesmente de sua existência no espaço e no tempo. A materialidade é medida pela massa, inércia e resistência" (FROHMANN, 2008 , p.22) e se insere na trama de institucionalidades em cujas propriedades (manipuláveis) encontram nos documentos tessitura, pois são eles que "[...] circulam através e dentre as instituições [apresentando] uma materialidade pronunciada" (FROHMANN, 2008, p.24). O documento se constitui, portanto, como a expressão material da informação; é um valor que se atribui ao objeto que pode ser institucionalizado, por exemplo, quando selecionado para constituir coleções.

O desenvolvimento de coleções - embora com motivações que podem remeter a tempos e contextos remotos, desde a Antiguidade (POMIAN, 1984), ou não tão remotos, como na Modernidade (WEITZEL, 2012) - corresponde, em termos disciplinares, a um movimento biblioteconômico estadunidense influenciado pelos estudos organizacionais a partir da segunda metade do século XX, momento marcado pelo avanço técnico e tecnológico que culminou em diversas transformações nas práticas informacionais.

As bibliotecas e os espaços congêneres, a partir de então, têm se dedicado, de modo sistemático, ao planejamento de coleções (EVANS, 2000) haja vista a ampliação do oferecimento de produtos e serviços de informação no contexto tradicional (analógico) e contemporâneo (que inclui ainda realidades digitais e em rede) (TAMMARO; SALARELLI, 2008). 0 processo seleção, não apenas em bibliotecas, mas na diversidade de instituições informativas e documentais, vem demandando o estudo da validação da informação que adquire reconhecida relevância não apenas para o desenvolvimento de coleções, mas, também, por auxiliar ou direcionar processos subsequentes, tais como os de organização da informação e do conhecimento.

A organização do conhecimento é um campo de investigação no âmbito da ciência da informação (HJøRLAND, 2003) que busca "ordenar e suprir o conhecimento" (JAENECKE, 1994) previamente selecionado, trazendo subsídios teóricos e metodológicos para a elaboração de produtos documentais mediante a produção e a utilização de linguagens documentais, ou seja, constitui um trabalho intelectual que tem a organização do documento e da informação nele contida (conteúdo) como objeto de estudo. Portanto, o campo objetiva a produção e a utilização da metainformação para fins de organização, visando recuperação, acesso e uso da informação num sistema de armazenamento e recuperação.

O percurso histórico do campo pode ser interpretado em termos de tratamento temático da informação em três correntes centrais: catalogação de assunto (subject cataloguing), de influência estadunidense; indexação (indexing), de influência inglesa; e análise documental (analyse documentaire), de influência francesa (GUIMARÃES, 2008). A trajetória da última corrente adquire particular relevância haja vista que remete ao percurso do movimento bibliográfico em ascendência na segunda metade do século XIX (WOLEDGE, 1983) e que veio a culminar, já no século $X X$, na proposição da documentação como disciplina, sobretudo a partir da sistematização de Paul Otlet em seu Traité de Documentation, de 1934 (FAYET-SCRIBE, 2001).

A documentação tem como objeto o documento na condição de "[...] um suporte de certa matéria e dimensão [...] em que se incluem signos representativos de certos dados intelectuais." (OTLET, 1934, p. 43). A ampliação do conceito de documento observado no cerne da documentação também pode ser identificada em outros horizontes disciplinares, conforme se observa a seguir:

[...] a retomada [da] noção de biblos possibilitou que Otlet avançasse também comparativamente à noção de fonte documental da "História Positivista", pois, para este autor, o texto escrito não seria o único representante documental dotado de objetividade. Mesmo com esse 
avanço, é interessante observar que a persistência da noção de objetividade, atribuída ao documento, evidenciou a aproximação conceitual entre Documentação e "História Positivista" [emergindo] o primeiro momento da Documentação, de "fase positivista", que representa um período de transição da tradição rumo à inovação conceitual. Essa fase foi marcada pela acepção otletiana de documento após a década de 1930, quando o conceito foi formulado considerando os objetos produzidos pelo homem em direção ao conteúdo [do documento]. Tal ênfase consistiria o fator distintivo para a transformação do objeto em documento, sendo que a ação humana de agregar ao objeto uma função informativa lhe garantiria o status de objetividade. [...] Tal concepção foi o ponto de partida para que a [...] francesa Suzanne Briet (1951), em seu ensaio Qu'est-ce que la documentation?, ampliasse ainda mais o conceito. [...] emerge [daí] o segundo momento da Documentação, de "fase hermenêutica". Nesta fase é possível fazer um paralelo entre os avanços da concepção de documento encabeçados pelo movimento dos Annales e por Briet. A "fase hermenêutica" compreender-se-ia, portanto, após a década de 1950, na ocasião em que se destacaram as ideias de Briet (1951) e de seus seguidores Meyriat (1981), Escarpit (1981), Day (1997), Buckland (1997), entre outros. Os argumentos comumente empregados por esses autores demonstraram que [...] o documento será o produto de um processo de objetivação (valoração) num ato interpretativo e de atribuição de significados e sentidos, sob a influência dos aspectos subjetivos "condicionados" pelo contexto social e cultural com os quais os sujeitos necessariamente se relacionam. (RABELLO, 2011, p.140-141).

A citação propicia um diálogo entre a ampliação do conceito de documento para a documentação e para a historiografia em duas dimensões de representação. Na dimensão positivista, os saberes são orientados pela crença da "representação inequívoca da realidade" (RABELLO; RODRIGUES, 2014), seja para o caráter institucional de produção, armazenamento e organização dos conteúdos, mediante o controle da informação como peças de "[...] fatos, opinião ou ideias que podem ser processadas e gerenciadas em sistemas [...]" (HJORLAND, 2000, p. 32), para a arquivologia, para a documentação e, posteriormente, para a ciência da informação; seja para as possibilidades metódicas de busca da "essência" do documento, para a historiografia.

$\mathrm{Na}$ dimensão hermenêutica, a documentação passa a considerar a intencionalidade na atribuição de sentido aos objetos. Igualmente nessa direção, a historiografia, com os Annales e, posteriormente, com a nouvelle histoire, contribui para a politização do métier do historiador e dos cientistas sociais, quando considera que "todo documento é um monumento" (FOUCAULT, 2005; LE GOFF, 1994), ou seja, todo documento é um objeto com valor, uma escolha, uma expressão de poder, algo que o torna um referente para a representação da realidade e para a construção e a legitimação de discursos, havendo a influência de diferentes institucionalidades.

\section{DOCUMENTO E INSTITUCIONALIDADES}

0 documento é um objeto com valor. Esse valor é atribuído por sujeitos com alguma autoridade, seja reconhecida por outrem (sujeitos agindo em nome de alguma institucionalidade) ou por algum indivíduo que crê na própria autoridade. Em ambos os 
casos, há a seleção de algum objeto a partir da atribuição de sentido (validação da informação) atribuído pelo indivíduo inserido em alguma coletividade, em cuja institucionalidade pode atingir maior ou menor força de representação social em agrupamentos como família, colecionadores, associações, comunidades epistêmicas, dentre outros.

Atribui-se valor ao objeto tendo em vista sua potencialidade informativa ou de fonte de informação - algo que também pode ser interpretado como valor social - para utilização, seja ela uma consulta ou leitura (no sentido amplo do termo) ou armazenamento, custódia, organização, recuperação, disseminação, acesso, com o objetivo de atender demandas informacionais (de comunidades) variadas, tais como obtenção de conhecimento técnico e científico, acesso à memória, proveito econômico, experiência estética, dentre outras motivações.

Todo documento pressupõe um objeto, seja ele mais estável, de natureza analógica, ou menos estável, de natureza digital. Em ambas as naturezas há a possibilidade de analogia intermediada por máquina, embora apenas no caso dos recursos digitais esse modo de intermediação se apresenta como imperativo. A abstração dos registros representados numericamente, ou digitalmente, necessita de leitura e processamento em componentes ou dispositivos eletrônicos, computacionais.

0 documento traz a ideia de um objeto que contém alguma evidência, um dado com sentido - informação - que pode ser objetivado na produção do próprio objeto ou atribuído posteriormente, seja um objeto artificial ou natural. Se o documento é um objeto com valor informacional, logo nem todo objeto será um documento. Isso porque os objetos são produzidos ou encontrados na natureza para finalidades diversas e nem sempre são indagados com o objetivo de se atribuir algum predicado de fonte de informação.

A materialidade do documento não se restringe à fisicalidade do objeto, embora tal fisicalidade seja indispensável. Se o documento é um objeto com valor, portanto se constitui de carga simbólica que varia conforme o sentido atribuído à informação nele contida e a institucionalidade envolvida. Tal atribuição de sentido é constituída e constituinte da materialidade dos enunciados os quais, mesmo quando informalmente, circulam na sociedade e potencialmente provocam práticas institucionais.

Nessa direção, o documento é a materialização dos enunciados sociais quando apropriados e validados em contextos institucionais. Em tal materialidade encontra-se o modus tollens para a transformação do objeto em documento. A materialidade se sintetiza no conceito de documento como algum objeto físico com valor simbólico validado para determinada finalidade. 0 resultado do empreendimento permite delinear aquilo que se denomina de função documental.

A função documental é o produto da valoração do objeto por sujeitos em contexto institucional no sentido de transformá-lo em algo com alguma utilidade social. O objeto com função documental pode formar uma coleção, armazenada e organizada em diferentes espaços institucionais. Tais instituições, com características próprias, definem conceitualmente o objeto agora com alguma função à medida que a partir delas o documento pode adquirir adjetivações, como jurídico, administrativo, histórico, arquivístico, museológico, biblioteconômico, dentre outros exemplos, dotadas de peso simbólico atribuído pelas institucionalidades originárias.

Retornando ao argumento inicial, pensar a institucionalidade do documento implica em refletir sobre a atribuição de valor cuja autoridade é reconhecida por outrem. Um professor, um pesquisador, um profissional de qualquer campo do saber gozam, desde a sua formação até a sua atuação, de alguma autoridade. Nesse caso, a institucionalidade pressupõe o poder do sujeito com autoridade em julgar o objeto para 
defini-lo ou selecioná-lo como fonte de informação válida. O saber empregado será digno de confiança se reconhecido por outrem, pelos pares, por outros sujeitos também atuando em distintos contextos institucionais.

0 documento utilizado em contextos acadêmico-disciplinares - num modo de institucionalidade particular - traz consigo algum valor probatório. A evidência de algo contido no documento e utilizado no contexto acadêmico-disciplinar será recepcionada a partir da expectativa de provar algo, tanto para refutar como para afirmar determinado enunciado científico. A institucionalidade envolvida traz consigo algum olhar ou empreendimento classificatório ou representacional de autoridade.

Portanto, o documento validado institucionalmente pressupõe a relação saberpoder. Isso porque implica no poder expresso na prática social e discursiva - aqui também pensada como prática informacional - de algum sujeito com autoridade em cuja ação orientadora se baseia em algum saber. 0 saber é constitutivo e constituinte da autoridade e do poder de definir aquilo cuja evidência tenha algum sentido informação - de interesse social.

Na obra Vigiar e Punir, publicada em 1975, Michel Foucault aborda a relação saber-poder no bojo das por ele denominadas ciências "duvidosas", ou humanas e sociais, numa ocasião em que "[...] a genealogia pode perguntar sobre o papel histórico e político desempenhado por estas ciências", considerando o "[...] componente centrado na transformação histórica de vários regimes de poder e de verdade." (DREYFUS; RABINOW, 1995, p.130-131).

Os regimes de poder e de verdade, em diferentes conformações sociotécnicas, podem também ser considerados em termos de regimes de informação. As ações e práticas de informação, em tais regimes, trazem pistas da agência de autoridades no processo de validação da informação em diferentes campos do saber. Pode-se citar, por exemplo, os empreendimentos para a escrita da história ou para a representação da realidade social em outras disciplinas, para a atuação no âmbito burocrático-estatal ou privado ou, particularmente, para a atuação dos profissionais de informação em instituições informativas e documentais.

Autores como Joan M. Schwartz e Terry Cook sustentam a premissa de que instituições informativas e documentais, como os arquivos, bem como os registros ali armazenados e organizados "[...] necessitam sujeitar-se a um processo de 'interpretação contínua' entre produtores, guardiães e usuários” (SCHWARTZ; COOK, 2004, p.23), algo que reitera a concepção do documento como uma expressão de poder. 0 documento se forja, em produção e reprodução, não apenas nas mencionadas instituições, como é o caso do arquivo, da biblioteca, do museu, mas também em outros campos legitimadores.

Com efeito, para Lídia Freitas, os artefatos e os conteúdos informacionais são igualmente "[...] insumo das relações institucionais de poder." (FREITAS, 2012, p.69). Se não existe, conforme Schwartz e Cook (2004), práticas informacionais descompromissadas ou neutras por parte dos sujeitos envolvidos no âmbito institucional, logo, o engajamento também alcança, ou é orientado, pela sistematização dos saberes que "formam" - nos sentidos de compor campos acadêmicos que atuam na pesquisa, no ensino e na aprendizagem - a comunidade epistêmica em questão.

Considerando campos responsáveis pela formação de profissionais de informação, a investigação de Eduardo Murguia aborda o caso dos agenciamentos da ciência da informação pela biblioteconomia e arquivologia no Brasil como modo de validação social sustentada pela relação saber-poder. Segundo tal estudo, ambas as disciplinas encontrariam na ciência da informação a fundamentação teórica e a legitimação institucional para sua inserção no âmbito científico e acadêmico, ainda que "[...] as relações de poder entre as ciências não são constituídas de forma unidirecional, 
pelo contrário, existe um embate entre os saberes fundamentados em tradições e práticas diversas." (MURGUIA, 2014, p.4).

\section{CONSIDERAÇÕES FINAIS}

Reduzir o entendimento de documento à sua fisicalidade ou à "coisa" (matéria + forma + conteúdo temático/descritivo) pode ter alguma utilidade instrumental para determinadas práticas informacionais; no entanto, conforme observado, essa abordagem leva a uma perspectiva parcial do fenômeno. Pensar o documento como um valor - a partir das institucionalidades e da materialidade formadora ou desenvolvida mediante práticas sociais e discursivas, respaldado pela "dupla hermenêutica", de cunho epistemológico e político - amplia os horizontes interpretativos.

A ampliação de horizontes serve, dentre outros aspectos, para investigar a autoridade do sujeito - reconhecida por outrem - que valida o objeto em contexto institucional com vistas à atribuição de sentidos formativos do documento. Com efeito, a transformação do objeto em documento tem em tal validação o processo de atribuição de valor a algo que potencialmente servirá de fonte de informação ou evidência e que poderá ser traduzido em termos de prova, por exemplo, no âmbito acadêmicodisciplinar para a "representação da realidade" e/ou para a "legitimação de discursos".

Se a materialidade do documento transcende a fisicalidade do objeto, haja vista a dimensão simbólica e política inerente, alguns caminhos apresentam-se promissores para a consideração dos horizontes que a perspectiva aponta. A institucionalidade, pensada em termos socioculturais (cultura material), ou em termos políticos, econômicos e éticos (regimes de informação), encontra nas ações e práticas informacionais rastros para compreender o fenômeno da validação da informação.

Em meio a tais práticas, disciplinas particulares, como a diplomática, se apresentam como um dos primeiros saberes sistematizados voltados para uma espécie de "validação da informação", algo em certa medida incorporado como procedimento metódico da historiografia positivista e, posteriormente, incorporado e adaptado pela arquivologia como recurso para o controle dos documentos gerados na burocracia moderna.

Igualmente como particularidade das ações e das práticas informacionais em instituições informativas e documentais, outras práticas de validação têm se destacado, como aquelas realizadas em processos de desenvolvimento de coleções ou de organização da informação e do conhecimento. Os documentos, como expressões materiais da informação em instituições corroboradas por tais práticas, adquirem identidade quando a eles lhe atribuem determinada função.

0 caráter não neutro e, por vezes, deliberadamente engajado na validação do objeto em algo com sentido - os sujeitos com autoridade de validação da informação carregam consigo visões de mundo traduzidas, por exemplo, em métodos e técnicas travestidos de imparcialidade - auxilia a pensar o documento não apenas com valor epistemológico para algum campo do conhecimento, mas como produto político da relação saber-poder, sintetizada na palavra monumento.

A monumentalização dos documentos vem sendo, nalguma medida, tematizada nos âmbitos das teorias historiográficas - primeiramente com os Annales e, posteriormente, com a nouvelle histoire - e das demais ciências sociais, dentre outras, com a teoria foucaultiana ou com as reflexões nos campos das ciências da documentação e da informação, na tentativa de se desnaturalizar conhecimentos até então secularizados pelo positivismo e por saberes e teorias que nele se inspiram. Combatem-se tais concepções que compartilham da crença na possibilidade de se 
compreender o mundo e os fenômenos como algo neutro, com pouca ou quase nenhuma complexidade, de modo apolítico.

0 construto documento-monumento, a contrapelo, é formulado por meio do reconhecimento de distintos nexos e da tensão política pressuposta na relação saberpoder, forjada institucional e disciplinarmente. A natureza política do documentomonumento ensina que este serve de fonte de legitimação ou de criação de práticas discursivas e/ou de recurso material para formar infraestruturas diversas, redes, coleções, fundos de arquivo, bases de dados, banco de dados, dentre outras. Adere a regimes de poder e de verdade os quais, quando investigados, trazem pistas da configuração do mundo da vida.

\section{REFERÊNCIAS}

APPADURAI, A. Introdución: las mercancías y la política del valor. In: . (Ed.). La vida social de las cosas: perspectiva cultural de las mercancias. México: Grijalbo, 1991. p.17-87.

BLOCH, M. Introdução à história. Ed. rev. aum. e criticada por Étienne Bloch. [S.I.]: Forum da História/Publicações Europa-América, 1997.

BOURDIEU, P. Espírito do Estado: gênese e estrutura do campo burocrático. In: Razões práticas sobre a teoria da ação. 4.ed. Campinas, SP: Papirus, 1996. p.91-135.

BRIET, S. Qu'est-ce que la documentation? Paris: Éditions Documentaires Industrielles et Técnicas, 1951.

BUCAILLE, R.; PESEZ, J.-M. Cultura material. In: ENCICLOPÉDIA EINAUDI. Lisboa: Imprensa Nacional; Casa da Moeda, 1989. v.16.

BUCKLAND, M. K. Information as thing. JASIS, v.45, n.5, p.351-360, 1991.

BURKE, P. Abertura: a nova história, seu passado e seu futuro. In: (Org.). A escrita da história: novas perspectivas. São Paulo: UNESP, 1992. p.7-37.

DREYFUS, H. L.; RABINOW, P. Genealogia do indivíduo moderno: a analítica interpretativa do poder, da verdade e do corpo. In:___. Michel Foucault: uma trajetória filosófica: para além do estruturalismo e da hermenêutica. Trad. Vera Porto Carrero. Rio de Janeiro: Forense Universitária, 1995.

DURANTI, L. Diplomática: usos nuevos para una antigua ciencia. Trad. Manuel Vászquéz. Carmona: S \& C Ediciones, 1995.

EVANS, G.E. Developing library and information center collection. 4.ed. Englewood: Libraries Unlimited, 2000.

FAYET-SCRIBE, S. Histoire de la documentation en France: culture, science et technologie de l'information: 1895-1937. Paris: CNRS, 2001.

FONSECA, M. O. Arquivologia e ciência da informação. Rio de Janeiro: FGV, 2005.

FOUCAULT, M. As palavras e as coisas. São Paulo: Martins Fontes, 1999.

A arqueologia do saber. Lisboa: Almedina, 2005. 
. Nietzsche, a genealogia e a história. In: Microfísica do poder. 12.ed. Rio de Janeiro: Ed. Graal, 2002. p.15-37.

FREITAS, L. S. Documento e poder: uma arqueologia da escrita. Morpheus, Ano 9, n.14, p.58-73, 2012. Disponível em: <http://www4.unirio.br/morpheusonline/numero142012/artigos/lidia_pt.pdf>. Acesso em: 29 jul. 2014.

FROHMANN, B. Taking policy beyond information science: applying the actor network theory for connectedness: information, systems, people, organizations. In: ANNUAL CONFERENCE CANADIAN ASSOCIATION FOR INFORMATION SCIENCE, 23., 1995. Proceedings... Edmonton: Alberta, 1995. Disponível em: <http://www.fims.uwo.ca/people/faculty/frohmann/Documents/TAKING\%20INFORMATION\% 20POLICY\%20BEYOND\%20INFORMATION\%20SCIENCE.pdf>. Acesso em: 20 fev. 2014.

O caráter social, material e público da informação. In: FUJITA, M.; MARTELETO, R.; LARA, M. (Org.). A dimensão epistemológica da ciência da informação e suas interfaces técnicas, políticas e institucionais nos processos de produção, acesso e disseminação da informação. São Paulo: Cultura Acadêmica; Marília: Fundepe, 2008, p. 19-34. Disponível em: <http://repositorios.questoesemrede.uff.br/repositorios/handle/123456789/829>.A cesso em: 1 abr. 2014.

GINZBURG, C. Controlando a evidência: o juiz e o historiador. In: NOVAIS, F. A.; SILVA, R. F. da (Org.). Nova história em perspectiva. São Paulo: Cosac Naify, 2011. p. 342-358.

GONZÁLEZ de GÓMEZ, M. N. O caráter seletivo das ações de informação. Informare, v.5, n.2, p.735, 1999.

. Metodologia da pesquisa no campo da Ciência da Informação. R. Bibliotecon. Brasilia, v. 23/24, n. 3, p. 333-346, 1999/2000.

Cuestiones epistemológicas de la Ciencia de la Información y de la Bibliotecología. In: RENDÓN ROJAS, M. Á. Problemas sobre teoría y epistemología de la ciencia bibliotecológica y de la información: discusión y análisis. Ciudad de Mexico: UNAM, 2000. p.1-15. (Colección: Teoria y Métodos 1. Centro Universitario de Investigaciones Bibliotecológicas).

As relações entre ciência, Estado e sociedade: um domínio de visibilidade para as questões da informação. Ciência da Informação, v. 32, n. 1, p. 60-76, jan./abr. 2003.

. Novas configurações do conhecimento e validade da informação. In: ENCONTRO NACIONAL DE PESQUISA EM CIÊNCIA DA INFORMAÇÃO, 8., Salvador, 2007. Anais... Salvador: ANCIB; UFBA, 2007. Disponível em: <http://www.enancib.ppgci.ufba.br/artigos/GT1--177.pdf>. Acesso em: 3 fev. 2017.

As ciências sociais e as questões da informação. Morpheus, ano 9, n. 14, 2012. Disponível em: <http://www4.unirio.br/morpheusonline/numero142012/artigos/nelida_pt.pdf>. Acesso em: 29 jul. 2014.

Validade científica: da epistemologia à ética e à política. Liinc em Revista, v. 11, p. 339359, 2015. Disponível em: <http://revista.ibict.br/liinc/article/view/3649 >. Acesso em: 2 jul. 2016. 
- Habermas y Foucault: la búsqueda del discurso post-epistemológico sobre la ciencia.

Scire, v. 22, p. 45-56, 2016.

GRIGOLETO, M. C.; MURGUIA, E. I. As bases epistemológicas do patrimônio institucionalizado. In: ENCONTRO NACIONAL DE PESQUISA EM CIÊNCIA DA INFORMAÇÃO, 16., João Pessoa, 2015.

Informação, memória e patrimônio: do documento às redes. João Pessoa: ANCIB; UFPB, 2015. GT 1 - Estudos Históricos e Epistemológicos da Ciência da Informação. Disponível em:

<http://inseer.ibict.br/ancib/index.php/tpbci/article/view/194/243>. Acesso em: 03 fev. 2017.

GUIMARÃES, J. A. A dimensão teórica do tratamento temático da informação e suas interlocuções com o universo científico da International Society for Knowledge Organization (ISKO). Revista Ibero-americana de Ciência da Informação (RICI), v.1 n.1, p.77-99, jan./jun. 2008.

HJORLAND, B. Fundaments of Knowledge Organization. Know. Org., v.30, n.2, p. 87-111, 2003.

Documents, memory institutions and information science. Journal of Documentation, v. 56, n. 1, p. 27-41, 2000.

JAENECKE, P. To What end Knowledge Organization. Know. Org., v.21, n.1, p. 3-11, 1994.

LE GOFF, J. Documento/monumento. In:__. História e memória. Traduzido por Bernardo Leitão et al. 3.ed. Campinas: Ed. UNICAMP, 1994. (Coleção Repertórios).

MALISKA, M. A. Max Weber e o Estado racional moderno. Revista Eletrônica do CEJUR, v. 1, n. 1, ago./dez. 2006. Disponível em:

<http://ojs.c3sl.ufpr.br/ojs2/index.php/cejur/article/view/14830 >. Acesso em: 6 fev. 2014.

MEYRIAT, J. Document, documentation e documentalogie, Revue de Bibliologie, Schema et Schematisation, n.19, p.51-63, 1981.

MURGUIA, E. Documento e instituição: produção, diversidade e verdade. In: FREITAS, L. S.; MARCONDES, C. H.; RODRIGUES, A. C. (Org.). Documento: gênese e contextos de uso. Niterói, EdUFF, 2010. v. 1, p.123-140.

Saber poder: os agenciamentos da Ciência da Informação com a Biblioteconomia e Arquivologia no Brasil. InCID: R. Ci. Inf. e Doc., v. 5, n. 1, p. 4-26, mar./ago. 2014. Disponível em: <http://www.revistas.usp.br/incid/article/view/64335>. Acesso em: 4 jan. 2015.

NUÑEZ-CONTRERAS, L. Concepto de documento. In: . Archivistica: estudios básicos. Sevilla: Diputación Provincial, 1981. p.25-44.

OTLET, P. Traité de documentation : le livre sur le livre : théorie et pratique. Bruxelles : Mundaneum, 1934.

POMIAN, K. Colecção. In: ENCICLOPÉDIA EINAUDI. Lisboa: Imprensa Nacional - Casa da Moeda, 1984. v.1. Disponível em:

<http://flanelografo.com.br/impermanencia/biblioteca/Pomian\%20(1984b).pdf>. Acesso em: 16 jul. 2014.

RABELLO, R. A dimensão categórica do documento na Ciência da Informação. Encontros Bibli, v.6, p.131-156, 2011. Disponível em:

<http://periodicos.ufpb.br/ojs/index.php/pbcib/article/view/13237>. Acesso em: 1 abr. 2014.

. ; RODRIGUES, G. M. Prova documental: inscrições e materialidade. Tendências da

Pesquisa Brasileira em Ciência da Informação, v.7, n.2, p.1-21, 2014. Disponível em: 
<http://inseer.ibict.br/ancib/index.php/tpbci/article/viewArticle/151>. Acesso em: 10 maio 2016.

RABELLO, R. ; RODRIGUES, G. M. Documento, forma e materialidade: abordagens probatórias e representação da realidade. In: ENCONTRO NACIONAL DE PESQUISA EM CIÊNCIA DA INFORMAÇÃO, 17. 2016, Salvador. Anais... Salvador: ANCIB; UFBA, 2016. Disponível em: <https://drive.google.com/file/d/0B7rxeg_cwHajQjdFcWMxd1pFYk0/view>. Acesso em: 1 abr. 2017.

RICOEUR, P. Fase documental: a memória arquivada. In: A memória, a história, o esquecimento. Campinas: Ed. Unicamp, 2007.

RIEH, S. Y. Judgment of information quality and cognitive authority in the Web. JASIST, v.53, n.2, p.145-161, 2002.

.; BELKIN, N. J. Understanding judgment of information quality and cognitive authority in the WWW. In: ANNUAL MEETING OF THE AMERICAN SOCIETY FOR INFORMATION SCIENCE, 61., 1998. [S.l.]. Proceedings... [S.l.: s.n.], 1998.

2007.

; DANIELSON, D. R. Credibility: a multidisciplinary framework. ARIST, v. 41, p. 307-364,

SARACEVIC, T. Relevance: a review of and a framework for the thinking on the notion in information Science. In: BRAGA, G. M.; PINHEIRO, L. V. R. (Org.). Desafios do impresso ao digital: questões contemporâneas de informação e conhecimento. Brasília: IBICT; UNESCO, 2009. p.15-70.

SAVOLAINEN, R. Information behavior and information practice: reviewing the 'umbrella concepts' of information-seeking studies. Library Quarterly, v.77, n.2, p.109-132, 2007.

SCHWARTZ, J.M.; COOK, T. Arquivos, documentos e poder: a construção da memória moderna. Revista do Arquivo Público Municipal de Indaiatuba, v.3, n.3, p.15-30, 2004.

SOUZA, B. G.; MURGUIA, E. I. Documentação de fé: reflexões sobre ex-votos e a sala das promessas do Santuário Nacional de Aparecida. Tendências da Pesquisa Brasileira em Ciência da Informação, v. 5, n.1, 2012. Disponível em:

<http://inseer.ibict.br/ancib/index.php/tpbci/article/viewArticle/84>. Acesso em: 3 fev. 2017.

TAMMARO, A. M.; SALARELLI, A. A coleção digital. In: . A biblioteca digital. Brasília: Briquet de Lemos, 2008.

TOGNOLI, N. B. A construção teórica da Diplomática: em busca de uma sistematização de seus marcos teóricos como subsídio aos estudos arquivísticos. 2013, Tese (Doutorado em Ciência da Informação) - Universidade Estadual Paulista, Marília, 2013.

TRAGTENBERG, M. Burocracia: da mediação à dominação. In: Paulo: Ática, 1985. p. 186-219.

Burocracia e ideologia. São

WEBER, M. Burocracia. In: Ensaios de sociologia. 5. ed. São Paulo: LTC, 2002. p.229-282.

WEITZEL, S. R. Desenvolvimento de coleções: origem dos fundamentos contemporâneos. Transinformação, v.24, n.3, p.179-190, set./dez. 2012. Disponível em:<http://periodicos.puccampinas.edu.br/seer/index.php/transinfo/article/view/1201/1176>. Acesso em: 16 jul. 2014. 
WERSIG, G.; WINDEL, G. Information Science needs a theory of 'information actions'. Social Science Information Studies, v. 5, p.11-23, 1985.

WOLEDGE, G. "Bibliography' and "Documentation": words and ideas. Journal of Documentation, v.39, n.4, p.266-279, 1983. 